\title{
Students' Response to the Questionnaire about the Usefulness of Concept Maps for Problem-Based Learning and the Forms of Concept Maps
}

\author{
Bong Jin Kang and Seok Kon Kim
}

Department of Anesthesia and Pain Medicine, Dankook University, College of Medicine, Cheonan, Korea

\section{문제바탕학습에서 사용한 개념도의 \\ 유용성에 대한 학생의 설문반응과 개념도의 유형}

단국대학교 의과대학 마취통증의학교실

\section{강봉진, 김석곤}

Purpose: Concept maps have been studied and used in diverse ways in scientific fields. This study aimed to investigate the usefulness and limitations of using concept maps during problem-based learning (PBL) in Year 3 medical students.

Methods: After each PBL module, we gathered concept maps from each pair of students and questionnaires about the usefulness and limitations of concept maps, and analyzed them.

Results: There were two types of concept maps, with some modifications. The students felt that concept maps provided overall understanding, analysis, and reorganization of problem cases. But, they also criticized shortage of disciplines related to drawing skills and rationales for each type of map. A strong need for expert maps and feedback for students resulted.

Conclusion: For optimal use of concept maps, we recommend that the committee implements a plan to teach drawing skills, explains rationales for each type of map, and gives feedback to students.

Key Words: Problem-based learning, Concept formation

Received: November 6, 2008 - Accepted: February 4, 2009 Corresponding Author: Bong Jin Kang

Department of Anesthesia and Pain Medicine, Dankook University Hospital San 16-5, Anseo-dong, Cheonan 330-715, Korea

TEL) 041-550-6819 CELL) 019-249-4376 FAX) 041-551-9330 E-mail) anebjkang@hanmail.net
Korean J Med Educ 2009 Mar; 21(1): 67-74.

doi: 10.3946/kjme.2009.21.1.67.

(C) The Korean Society of Medical Education. All rights reserved. 


\section{서론}

문제바탕학습은 학습자 스스로 정보를 취득해 나가면 서 문제 해결에 이르기까지 통합적이고 유기적인 지식을 쌍아갈 수 있도록 하는 새로운 학습방법으로 자리 잡아 가고 있다[1]. 그러나 이 방법이 정착하는 데 있어서 여 러 형태의 장애물들도 제기되어 왔다. 복잡하고 생소한 교과과정 속에서 오히려 자발적이고 깊이 있는 학습을 하기 힘들어 하거나, 편법적으로 최종 결과만 조작적으 로 만들어내는 학습태도를 보일 수 있으며[2], 시공간 혹 은 인적 차원에서의 재원확보 문제나 교수, 학생들의 동 기와 흥미 수준을 지속시키는 것도 극복할 문제로 대두 되었다[1,3].

따라서 이런 문제점들을 보완하는 여러 대책이 필요하 다고 생각된다. 그 중 개념도는 새롭게 접하는 지식들 속 에 담긴 주요 개념들을 파악하고 기존의 선행지식과 함 께 조직적 통합 구성을 도모하여 깊이 있는 이해에 이르 도록 도와줄 수 있는 도구가 될 뿐만 아니라, 별도의 많 은 재원 없이 활용이 가능하므로 이를 문제 바탕학습 같 은 상황에 적극 도입한다면 상호보완적인 효과가 있다는 주장들이 나오고 있다[4,5,6].

개념도는 원래 Ausubel의 구성주의적 유의미 학습 이 론을 토대로 그 이론을 학습현장에서 구체화시킬 수 있 는 도구로서 개발, 시도되어온 것으로서 전통적 강의식 수업에서 먼저 활용되었고[4,7], 문제바탕학습 상황에서 도 활용되기 시작하여 $[4,5,8,9]$ 최근까지도 그 유용성[6] 에 대한 연구가 진행되고 있다.

따라서 이 연구는 문제바탕학습에서의 향후 보다 적절 한 개념도 활용방안을 모색하고자, 2008년도 문제바탕 학습에서 작성한 개념도의 유용성과 문제점에 대한 설문 응답 결과를 분석하여 개선 방향을 찾아보았으며, 또 작 성된 개념도 형태들을 관찰, 분류함과 아울러 형태에 관 한 학생들의 반응을 통해 이에 대한 향후 지침도 정하고 자 하였다.

\section{대상 및 방법}

\section{1. 연구대상과 개념도 교육}

이 연구는 임상실습 과정에 진입하기 전 4주간 problem-based learning (PBL)을 시행하는 단국대학 교 의학과 3 학년 학생 53 명을 대상으로 하였다. 학생은 공개된 소프트웨어인 CmapTools (IHMC, Pensacola, FL, USA; http://cmap.ihmc.us/)를 사용하여 개념도 를 작성하였다. 2007년도는 학생들에게 타 대학의 다양 한 개념도를 예시하는 것으로 개념도 작성 교육을 대신 하였다. 매주 사례 학습이 끝나면 조당 1 개씩 개념도를 작성하게 하였으나, 별도의 발표시간을 갖거나 평가에 반영하지는 않았다. 2008년도에는 개념도 사용을 좀 더 확대하고자 학생들의 문제바탕학습 오리엔테이션 때에 선배 학생이 개념도에 대한 소개와 작성법에 대한 간단 한 강의를 하였고, 전년도 학생의 개념도 예시물을 보여 주는 교육을 시행하였다. 또한 한 주 모듈이 끝나면 2, 3 명당 1 개씩 만들도록 함으로써 보다 많은 학생들이 이 학습도구의 효용을 경험하도록 하였고, 파워포인트를 이 용한 사례 발표회 때 개념도도 조별로 하나를 선정하여 함께 발표하도록 하였다. 그리고 문제바탕학습 평가에서 소그룹 학습에 임하는 태도 $40 \%$, 파워포인트발표 $15 \%$, 개인별 학습과제 $10 \%$, 성찰일기 $10 \%, 2$ 주마다 치르는 퀴즈에 $15 \%$, 개념도에 $10 \%$ 로, 전체에서 개념도 부분이 $10 \%$ 의 평가 성적을 차지하도록 하였다.

\section{2. 설문조사}

2008년 4주간 PBL을 시행한 후, 의학과 3학년 학생 53 명을 대상으로 설문조사를 시행하였다. 설문은 4문항 으로, 문항 1 은 개념도가 문제 바탕학습에 어떤 도움이 되는지에 대하여, 문항 2 는 개념도 작성의 장점과 작성 과정에서의 어려운 점이나 단점에 대하여, 문항 3 은 4 주 경과 시 어떤 점에서 개념도 작성이 용이하게 되었고 그 로 인해 느끼게 된 개념도의 장점에 대해서, 문항 4는 향 후 개선점에 대한 것이었다. 개방형의 질문으로 하였는 데, 그 이유는 선행 연구 중 본 연구 목적과 유사한 목적 
을 가지면서 설문을 제시한 논문을 발견할 수 없었고, 본 교의 경우 개념도 시행 경험이 많지 않아 개념도의 유용 성에 대한 기본적인 선별 수준의 설문을 개방형으로 제 시하는 것이 적절하다고 사료되었다.

\section{결과}

\section{1. 설문조사결과}

의학과 3 학년 학생 53 명 중 52 명이설문에 응답하여 설 문 참여도는 $98 \%$ 이었고, 4 개의 개방형 질문에 대하여 다양한 답변을 받을 수 있었다. 그러나 설문 내용 중 학 생들의 입장에서 중복된 질문이라고 여겨지는 경우가 많 았다. 예를 들어 '문항 2'는 개념도의 일반적인 장, 단점 이라고 생각되는 것을 쓰라는 질문이었으나 학생들은 $\mathrm{PBL}$ 상황에서의 장, 단점을 생각해보라는 뜻의 중복된 질문으로 대부분 간주하였으며, '문항 4' 역시 개념도작 업의 기술적인 측면에서 개선점을 써보라는 의도였으나 이 역시 위와 동일한 맥락에서 받아들였다. '문항 3'에 대 해선 대부분의학생이 "향상되었다"는 답변을 하면서 추 가로 구체적 근거를 좀 더 서술하였다. 이에 저자들은 모 든 학생들의 답변을 숙지한 후 다빈도로 나타나는 것들 을 다음과 같이 재분류하여 정리하였고, 개방성 설문의 성격상 정확한 응답 비율로 나타내지 못하였음을 밝힌 다.

\section{1) 문제바탕학습 중 시행한 개념도 작성의 유용성에 대한 반응}

'문항 1'과 '문항 2'를 통해 개념도 작성의 유용성에 대 한 반응을 파악할 수 있었다. 가장 흔한 반응은 사례를 다루면서 여러 학습 과제를 나누어 공부를 하느라 전체 적인 학습 상황을 파악하기 힘들었으나, 개념도 작업을 하는 가운데 어느 한 부분에 매몰되지 않고 전체를 한눈 에 연결하여 볼 수 있게 된다는 점이었다.

그 외 개념도 작업 시 선 하나를 연결하는 것도 정확히 하려면 전체를 다 파악하고 해야 한다는 점을 인식하게 되어 개념간의 연관성에 대한 이해를 높이는 계기가 되 었다는 반응, 일직선적인 추론을 넘어 다원적인 추론이
수월해진다는 반응, 근접한 정보들도 연관 개념에 따라 재배치를 하게 되므로, 뒤섞인 정보와 이야기로부터 유 기적인 재통합이 가능해진다는 반응, 각자가 생각하는 가설들을 합리적인 근거에 의거하여 정리해보는 기회가 되는 점 등 비교적 다양한 점들을 열거하였다.

한편 1주차에서 4주차로 가면서 반복시행에 따른 이점 에 대해서는, 소프트웨어 사용에 익숙해지고 개념도 목 적에 대해서도 더 잘 이해하게 되면서 보다 많은 내용을 연관시킬 수 있었고 신속한 작업이 가능했다는 의견이 많았다. 또 반복적인 사용의 주목할 만한 효과로 환자의 사례를 접할 때, 어떤 순서로 접근하는지 깨닫는데 도움 이 된다고 하였다. 즉 개념도 형태로 연상하면서, 다음 단계의 할 일, 진단 시 고려할 일 등을 자연스럽게 생각 하게 된다고 하였다.

\section{2) 개념도 작성 방법 상의 문제점과 대책}

'문항 2'와 '문항 4'를 통해 개념도 작성 방법상의 문제 점과 그 개선책들을 파악할 수 있었다. 문제바탕학습 과 정에서 개념도에 들어갈 여러 사실이나 개념들이 이미 도출되어 있어서, 개념 선정에 따른 어려움은 호소하지 않았다. 그러나 개념 간 연결을 어느 만큼 할지, 또 어떤 형태로 만들어야 하는 지 등에 있어서 혼란스러움을 호 소하였고, 따라서 이런 세부적인 작성 과정에 대한 지침 이나, 모범 개념도 및 되먹임이 필요하다는 것을 많은 학 생이 지적하였다.

또한 사용 소프트웨어에 대해서도 다양한 화살표나 선 그리기, 한글 넣기, 그림 첨부 등의 기능이 없지는 않았 으나 익숙해질 때까지 많은 불편을 호소하였다. 또 개념 도의 내용과 구성에선 별 차이를 느끼지 못하면서도 디 자인 같은 형식적인요소에 따라 우열이 가려지는 것 같 다는 의견을 다수가 제시하면서, 그런 형식적 요소에 골 몰하게 되는 것을 시정하도록 요구하는 경우가 많았다.

\section{3) 운용 제도상의 문제점과 대책}

학생들은 2 명당 1 개의 작성 지침을 조별 1 개 혹은 1 명 당 1 개의 지침으로 바꿔 주기를 요청하는 경우가 많았 다. 전자의 의견은 한 조의 토의 결과 만들어지는 개념도 들이 대개 비슷하여 조당 여러 개를 만들 필요를 못 느낀 다는 생각 때문이었다. 반면 후자의 의견은 두세 명이 만 드는 경우 좀 더 자신 있는 사람이 혼자 다하게 되는 경 
우가 많아지게 되고 이런 경우 잘하는 사람이 손해의식 을 가지게 되거나, 못하는 사람은 포기하기 쉽다는 점이 지적되었다.

또한 개념도 제출 시한을 그 주의 금요일 파워포인트 발표시간에 맞추어 완료하도록 추진한 것에 대해 많은 학생들이 과도한 부담을 호소하는가 하면, 부실한 개념 도로 이어짐을 지적하였다.

\section{4) 개념도의 내재적 한계점과 대응 방안}

개념도의 단점과 관련한 학생들의 설문 응답 중, 개념 도 자체가 갖는 한계점이라고 생각되는 것들에 대한 의 견들은 다음과 같았다. 우선 좋은 개념도를 만들기 위해 선 사례에 대한 깊이 있는 공부와 이해가 선행되어야 한 다는 반응이 있었다. 또한 문제 바탕학습 중에 경험했던 다양한 사고 과정들을 개념도라는 단순한 형식에 다 담 아내는 것이 무리라는 의견도 나왔다.

\section{2. 개념도 유형}

학생들은 크게 두 가지 형태의 개념도를 작성하였다. $\mathrm{A}$ 형은 사례에 나타난 모든 자료를 열거하면서 가능한 진단들을 감별해가는 형태의 것(부록 1)이었는데, 저자 들이나중에 인지하게 된 사실은 이 형태가 소그룹 별로 발표하게 되는 파워포인트 자료와 접근 방식이 동일하여 거의 중복된 작업의 느낌을 준다는 것이었다. 또 이 형태 에 대한 이해가 모든 자료를 최대한 연결하는 것으로 되 어 있었고 학생들에게도 그런 지침이 전달되어있어, 결 국 많은 선을 그려 넣은 개념도들이 만들어지게 되었다. 이는 일견 많은 연결선과 교차연결을 갖는 수준 높은 개 념도라는 느낌을 주기도 하나, 때론 혼란스럽고 불필요 한느낌을 호소하는 경우가 많아 중요 개념 위주로의 개 선이 필요함을 알 수 있었다. B형은 주증상에서 시작하여 여러 가능성을 감별하고 진단과 처치에 이르는 형태로서, 위계(hierarchy)형(부록 2), 바퀴살(spoke)형, 그물망 (network)형, 혼합형 등 다양한 변이 형태들이 있었다.

\section{고찰}

개념도는 복잡한 상황 속의 사실이나 생각들을 개념화
하고, 그 연결 상태를 서술 방식이 아닌 일목요연한 시각 적 방법으로 정리하는 학습방법으로 개발되었다. 이를 통해 개념들의 조직적인 연결과정을 통해 궁극적으로 깊 이 있는 이해를 도모하고, 학습주제에 대한 흥미 증가와 기억률의 향상 효과를 거둘 수 있다고 생각된다[10,11]. 개념도의 이런 다양한 잠재적 효용성을 기대하고 문제바 탕학습 상황에 적용하여 본 후, 설문을 통해 개념도의 유 용성과 한계점들에 대한 다양한 의견들을 파악할 수 있 었고, 개념도 형태에 따른 적절한활용 방안에 대한 재고 및 평가상 문제점들에 대해서도 고찰하는 기회가 되었 다.

학생들은 대체로 전체적인 시각을 얻게 도와주고, 문제 해결을 위한 사고 과정을 개념도 작업하는 가운데 새롭 게 정리해볼 수 있도록 도와주는 유용한 도구라는데 의 견을 같이 하였고, 이 외에도 다양한 장점들을 거론하여 문제바탕학습의 목적을 충분히 보완할 수 있는 도구임을 알 수 있었다. 특히 개념도는 익숙하게 교육만 된다면 그 자체로 많은 재원을 요구하지 않으면서 다수의학생들의 구조적 지식을 평가할 수 있는 장점도 빼놓을 수 없다. 실제적 outcome과의 연관성을 규명한 연구도 조금씩 이 루어지고 있는데, Jitlakoat[12]에 따르면 간호대 학생들 을 대상으로 12 회 이상의 충분한 개념도 작업 후, 임상수 기능력의 변화를 측정한 연구에서는 병력청취, 이학검 사, 감별진단능력, 즉각적 치료 분야 등 모든 분야에서 큰 향상을 보여주었다. Roberts et al.[13]은 영양 요법 전공학생들을 대상으로 개념도 위주의 학습을 시도한 연 구에서 영양치료에 관한 지식 뿐 아니라 자발적 학습 능 력, 비판적 사고 능력, 문제 해결 능력 및 소그룹 협동 능 력 등에서 향상된 결과를 보고 하였다.

개념도 작업의 문제점 혹은 한계와 관련하여서는 제작 일정이나 개념도내용에 따른 구성 형태 같은 실행지침 관련 사항, 소프트웨어 사용상의 문제점 및 개념도 자체 의 내재적한 계점에 이르기까지 다양한 문제점들을 인식 할 수 있었다. 우선 개념도 제출일은 그 다음 주 월요일 로 하는 것이 합리적임을 알게 되었다. 개념도의 내용적 구성 형태로서는A, B의 두 가지가 있었는데, 이 중 A형 은 파워포인트 발표와 내용이 비슷하므로 파워포인트 발 표를 대치하는 식으로 하거나 혹은 추후에는 $\mathrm{A}$ 형 자체 
를 권장하지 않는 쪽으로 유도하여야 할 것으로 생각되 었으며, B형의 경우 개인별로 하나씩 사례를 다시 복습 하는 차원에서 제작하는 것이 좋겠다는 생각을 하게 되 었다. 또 사용 소프트웨어에 익숙해지는 데 따른 노력을 최소화할 필요가 강력히 제기되었는데, 이를 위해서는 2 학년 통합강의 등의 기회를 통해 시연 및 학생 실습의 기 회를 줄 수 있어야 함을 알게 되었다. 동시에 준비 사항 으로서 모범적인모델 개념도를 제시하고 학생들의 작업 에 대한 되먹임을 해주는 것이 필요함을 알게 되었다. 그 러나 이런 준비들은 개념도 학습 시행자들에 대한 체계 적인 교육이 우선되어야 할 것으로 보여 학교 차원의 꾸 준하고 점진적인 지원이 필요하다고 생각된다.

개념도의 내재적 한계점과 관련된다고 생각되는 의견 중 하나는 개념도가 PBL 중에 이루어진 다양한 학습 내 용들을 충분히 반영하기에 역부족이란 것이었다. 이 의 견은 교과 과정이 진행되면서 학생들의 이해 수준이 깊 어짐에 따라 개념도의 복잡성도 증가된다는 보고들 $[6,14]$ 에 비추어 볼 때 그 가능성을 충분히 인식하지 못 한 성급한 의견으로 볼 수도 있다. 그러나 이 의견의 유 의미성을 증거하는 연구들도 있는 바, 기존의 개념도가 개념 간 연결을 통한 개념 이해의 확장 효과는 비교적 손 쉽게 성취할 수 있으나, 현상의 기전을 충분히 설명하는 개념연결은 쉽게 일어나기 어려우며 이를 위해서는 세심 한 사전계획과 지침 혹은 강의들이 준비되어야 한다는 주장이 있다[15]. 이런 주장은 또한 PBL 과정 자체도 기 초의학적 기전에 대한 충분한 배움의 기회를 제공하는 시행 지침이 마련되지 않으면, PBL 학습 후 학생들의 기 초 의학적인이해가 매우 부족하기 쉽다[16]는 주장과도 일맥상통하는 것이다.

한편 얻어진 $\mathrm{A}, \mathrm{B}$ 형의 개념도 형태 외에도 문헌적으 로 문제바탕학습과 관련하여 여러 다른 형태의 개념도들 도 소개되고 있다. 즉, 주어진 사례의 여러 증상들을 학 습 후 알아내게 된 여러 인과 관계들을 통해 최종 원인까 지 연결시키는 사례지도(case mapping)형 개념도가 있 는가 하면[5], 특정 질환이나 증후군을 개념 정리의 중심 에 두고 그 원인, 증상, 기전, 진단, 처치 등으로 나누어 전통적 방식의 교과서 내용처럼 정리하는 개념도를 만들 어가는 경우도 있고[8], 사례 관련내용 중 치료계획, 진
단, 위험도 예측 등과 같은 한 가지 세부 관심 주제를 선 정하여 그것을 좀 더 상세히 개념도화 하는 경우 $[12,17]$ 등 다양한 목적 하에 개념도가 제작되어 왔다. 그러나 각 경우에 있어서도 개별적 내용의 구성형태는 역시 다양한 개인적 특성 차가 드러나는 결과를 보여준다고 보고하고 있으며[12,17], Johnstone \& Otis[18] 역시개념도가 각 자의 상황에서 이해하는 바대로 독특한(idiopathic) 형 태를 드러내는 것이 일반적이라고 주장하였다. 본 조사 에서도 학생들은 오리엔테이션과 지침 등을 통해 크게 $\mathrm{A}, \mathrm{B}$ 두 가지 유형의 개념도를 제작하였으나, 각 유형 안에서 어느 정도 다양하고 특이적인 제작을 함을 알 수 있었다.

한편 개념도 전체적인 외관의 측면에 관하여서도 위계 형, 바퀴살형, 그물망형, 혼합형 등 다양한 변형이 나타 날 수 있다고 보고하고 있는데[18,19,20], 저자의 연구에 서도 여러 다양한 외형을 보여주고 있었다.

따라서 개념도 형태에 대한 방침을 정함에 있어, 어느 정 도의 작성목적과 그에 따른 형태에 대해 소개하는 것은 필요하지만, 각자의 구체적 작업과 관련하여서는 좀 더 개인적 소신을 반영하여 진행하도록 해야 한다고 생각한 다. 또한 개념도 시행에 있어서 형태 등 세부 사항에 지 나친 고민을 하기보다 과감하게 일단 시작하고 점차 익 숙해지도록 유도하였을 때 괄목할 만한 좋은 성과로 이 어졌다는 보고들은 주목할 필요가 있다고 생각된다 [12,17].

결론적으로 본 연구를 통해 개념도는 문제바탕학습의 취지를 잘 보완해줄 수 있는 좋은 도구가 됨을 확인할 수 있었다. 그러나 실행 지침에 있어 여러 부분에서의 개선 노력이 필요하며 이를 위해서는 좀 더 체계적이고 지속 적인 학교 당국의 지원이 필요함을 알게 되었다.

\section{REFERENCES}

1. Wood EJ. Problem-based learning. Acta Biochim Pol 2004; 51: XXI-XXVI.

2. Lloyd-Jones G, Hak T. Self-directed learning and student pragmatism. Adv Health Sci Educ Theory 
Pract 2004; 9: 61-73.

3. So YH, LeeYM, Ahn DS. Anstudent's evlauation of the implementation of problem-based learning. Korean J Med Educ 2005; 17: 49-58.

4. Pinto AJ, Zeitz HJ. Concept mapping: a strategy for promoting meaningful learning in medical education. Med Teach 1997; 19: 114-121.

5. Guerrero AP. Mechanistic case diagramming: a tool for problem-based learning. Acad Med 2001; 76: 385389.

6. Rendas AB, Fonseca M, Pinto PR. Toward meaningful learning in undergraduate medical education using concept maps in a PBL pathophysiology course. Adv Physiol Educ 2006; 30: 23-29.

7. Edwards J, Fraser K. Concept maps as reflectors of conceptual understanding. Res Sci Educ 1983; 13: 19-26.

8. Edmondson KM. Concept maps and the development of cases for problem-based learning. Acad Med 1994; 69: $108-110$

9. Weiss LB, Levison SP. Tools for integrating women's health into medical education: clinical cases and concept mapping. Acad Med 2000; 75: 1081-1086.

10. Wandersee JH. Concept mapping and the cartography of cognition. J Res Sci Teach 1990; 27: 923-936.

11. Romance NR, Vitale MR. Concept mapping as a tool for learning: broadening the framework for studentcentered instruction. Coll Teach 1999; 47: 74-79.

12. Jitlakoat Y. The effectiveness of using concept map ping toimprove primary medical care nursing competencies among fourth year Assumption University nursing students. AU J Technol 2005; 9: 111-120.

13. Roberts CM, Sucher K, Perrin DG, Rodriguez S. Concept mapping: aneffective instructional strategy for diet therapy. J Am Diet Assoc 1995; 95: 908-911.

14. West DC, Pomeroy JR, Park JK, Gerstenberger EA, Sandoval J. Critical thinking in graduate medical education: a role for concept mapping assessment? JAMA 2000; 284: 1105-1110.

15. van Boxtel C, van der Linden J, Roelofs E, Erkens G. Collaborative concept mapping: provoking and supporting meaningful discourse. Theory Pract 2002; 41: 40-60.

16. Glew RH. The problem with problem-based medical education: promises not kept. Biochem Mol Biol Educ 2003; 31: 52-56.

17. All AC, Havens RL. Cognitive/concept mapping: a teacher strategy for nursing. J Adv Nurs 1997; 25: 1210-1219.

18. Johnstone $\mathrm{AH}$, Otis $\mathrm{KH}$. Concept mapping in problem based learning: a cautionary tale. Chem Educ Res Pract 2006; 7: 84-95.

19. Ruiz-Primo MA, Shavelson RJ. Problems and issues in the use of concept maps in science assessment. J Res Sci Teach 1996; 33: 569-600.

20. Stuart HA. Should concept maps be scored numerically? Int J Sci Educ 1985; 7: 73-81. 
부록 1. This concept map details a case of nephrotic syndrome. It begins with the data set, suggests hypothetical diagnoses, and rules out some of them with the following data. Its appearance is neither hierarchial nor spoke-shaped

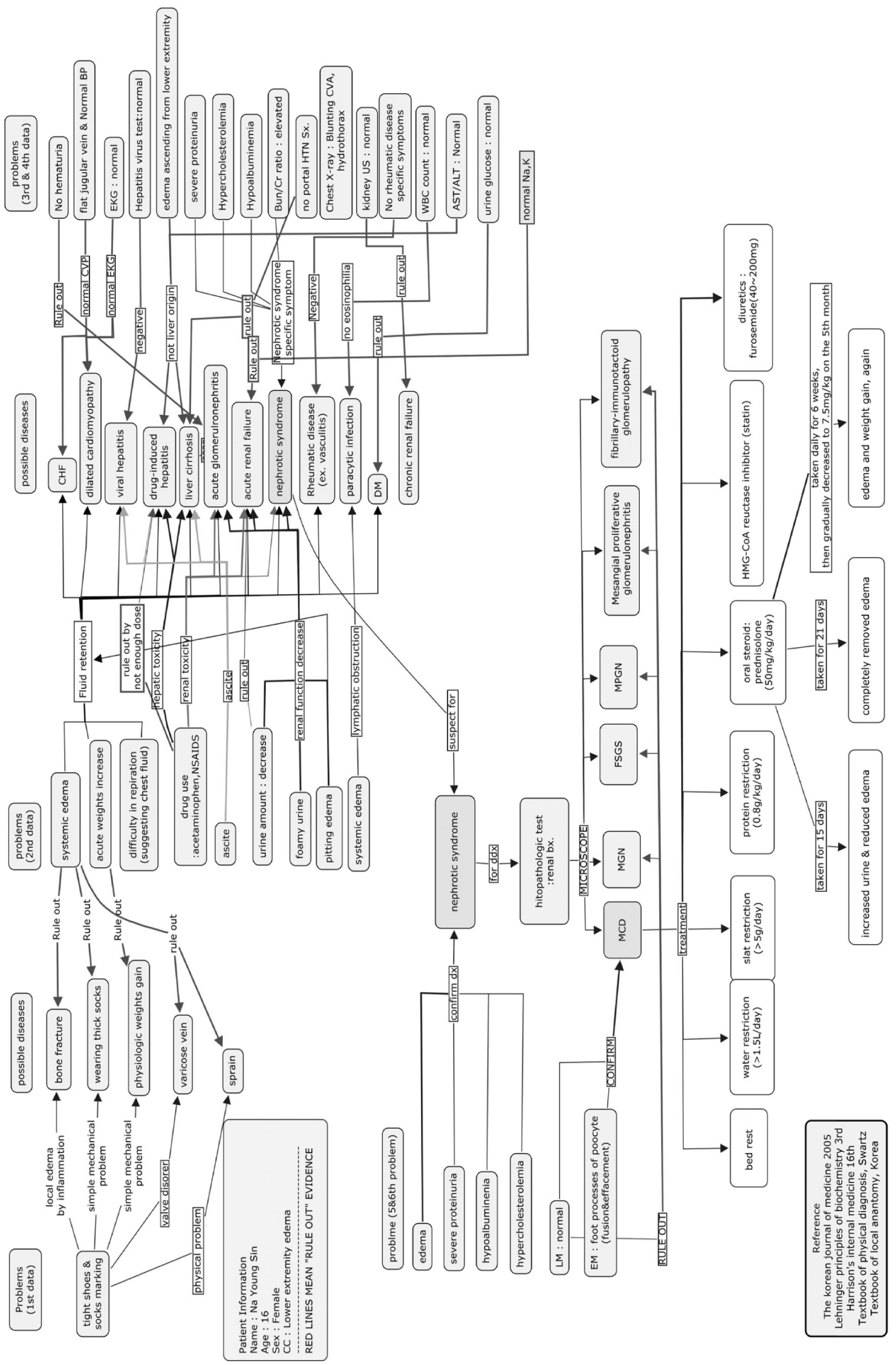


부록 2. This concept map also outlines a case of nephrotic syndrome. It starts from the chief complaint and reveals its diverse etiologies in a hierarchial organization, with some modifications

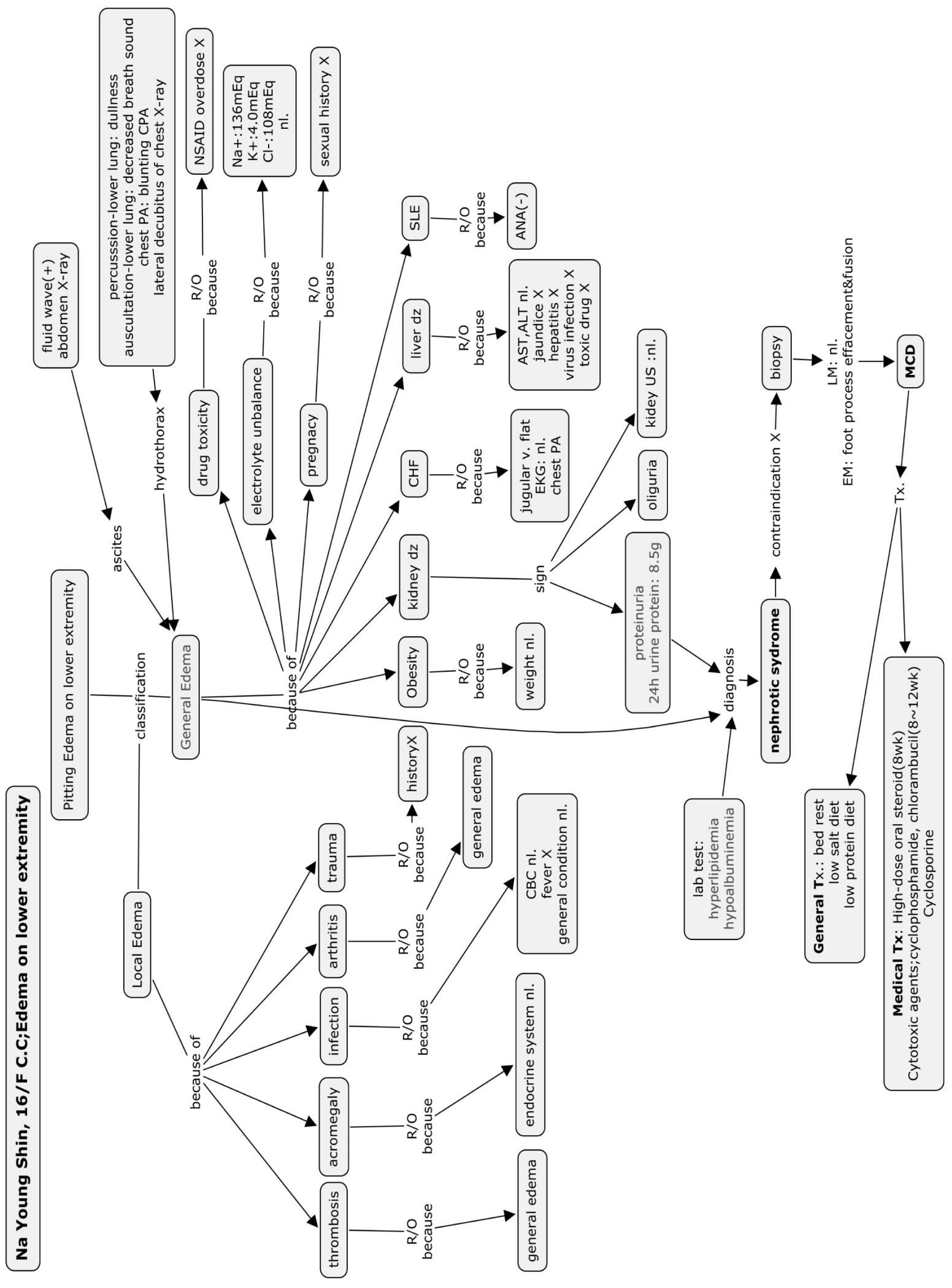

